\title{
The complexity of indigenous evaluation
}

\section{Robert Picciotto}

This article was triggered by the COVID-19 pandemic and the antiracist protests that have swept the world. Both developments have brought to the surface the social inequities and the existential risks that face humanity in a complex and interconnected world. Indigenous evaluation is highly relevant to both predicaments. Since I am not an indigenous evaluator, I cannot do justice to the wealth and diversity of the indigenous evaluation experience. All I seek to do is to connect indigenous evaluation to complexity thinking, a mindset that is more needed than ever.

\section{Introduction}

This article was triggered by the COVID-19 pandemic and the antiracist protests that have swept the world. Both developments have brought to the surface the social inequities and the existential risks that face humanity in a complex and interconnected world. Indigenous evaluation is highly relevant to both predicaments. Since I am not an indigenous evaluator, I cannot do justice to the wealth and diversity of the indigenous evaluation experience. All I seek to do is to connect indigenous evaluation to complexity 
thinking, a mindset that is more needed than ever.

Indigenous peoples are 500 million strong-over $6 \%$ of the global population - that is, more than the populations of the United States and Russia combined. They occupy or use a quarter of the world's surface, and they act as stewards of $80 \%$ of the world's remaining biodiversity. Scattered over 90 countries, their cultures, languages, customs, and institutions are highly diverse and distinct from those of the societies in which they are embedded.

Yet, indigenous peoples hold similar values; their identities are linked to the land on which they live; they share a common heritage of oppression by outsiders; and they are all committed to preserve, develop, and transmit to future generations their ethnic identity, their customs, their social institutions, and their legal systems. This helps explain why indigenous evaluation is a coherent social practice that has brought together similarly oriented evaluation practitioners from all corners of the world.

The article is in five parts. First, it describes the slow rise of complexity in knowledge creation within Western societies. Second, it shows that indigenous evaluation is a complex adaptive system. Third, it suggests that indigenous evaluation is ideally placed to confront the dominant ideology that dominates evaluation today. Fourth, it draws the epistemological implications of this confrontation for the rest of the evaluation community. Fifth, it concludes.

\section{The age of complexity}

Indigenous cultures embrace complexity: they invariably hold a holistic view of the world and their approach to knowledge creation is transdisciplinary (Apgar et al., 2009). By contrast, the Cartesian mental model that took a firm hold of Western societies in the 18th century steered Enlightenment thinking away from complexity towards rationalist, linear, and predictable concepts that generated 
a machine metaphor for the workings of society and propelled the Industrial Revolution forward through standardised and hierarchised production methods that induced urbanisation, social dislocation, and loss of worker autonomy.

In the scientific realm, Western knowledge creation became fragmented. While specialisation fuelled extraordinary scientific and technological progress, it induced, at the same time, a value-free conception of science as well as a strict segregation between the physical, natural, and social sciences from one another, each operating in its own silo. This led policy makers to shape their decisions as if natural resources are infinite even though human beings live in a closed system of restricted boundaries.

Oversimplifying reality and conceiving of the world as an open system without boundaries, as Galileo and Descartes did, has had fateful consequences: new, proliferating, intractable and deadly complexities (climate change, biodiversity extinction, pandemics, etc.) now threaten humanity. By contrast, all indigenous cultural and social practices embrace a cosmological world view that induces a deep respect for nature and promotes socially and environmentally sustainable practices (Latour, 1991).

The limits of Cartesian science are now widely acknowledged. It has become clear that the clockwork conception of the universe does not jibe with chaotic dynamics, the patterns of animal behaviour, or even common-sense observations about the natural and social world. Why has Cartesian logic failed to bridge the gap between Einstein's general relativity equations and Bohr's quantum theory? How do thousands-strong flocks of birds find their way over huge distances without central guidance? What invisible hand shapes the behaviour of markets that connect billions of independent agents?

Evidently, the reductionist model of science is incomplete. It only captures a shadow of the real world. Its basic postulate is erroneous: 
not all natural and human systems are complicated machines that can be disassembled in distinct parts to elucidate their functioning and ascend inexorably to knowledge of the complex. Thus, there is ample support for Stephen Hawking's view that the 21st century is the "century of complexity". It is time for indigenous evaluation to act as a major driver of mainstream evaluation thinking.

Knowledge creation must contend with a world that is inherently complex from the molecular to the global level. Beyond physics and energy, life has its own rules that linear dynamics cannot adequately account for. The mechanistic conception of the natural and social world is no longer tenable. It has been successfully challenged in biology, meteorology, epidemiology, linguistics, cybernetics, communication, computer science, and artificial intelligence. Evaluation should follow suit.

Indigenous evaluation is highly relevant to the contemporary mainstream evaluation enterprise. Indigenous communities have always recognised that the world is not only complicated, but also complex in the very sense evoked by the terms described in the next section. Hence indigenous evaluation can act as a transmission belt to public policy around the world by linking decision making to vital ancestral knowledge and expertise on how to adapt, mitigate, and reduce climate change and natural disaster risks.

\section{Indigenous evaluation is complex}

Complicated mechanical systems (e.g., a car or a plane) share the characteristics of complex systems in the sense that their whole is greater than and different from the sum of their parts (emergence) but they are not complex because the relationships that define them are largely linear. By contrast, complex systems follow nonlinear rules and evolve from initial conditions in ways that generate outcomes that are not driven solely by the parts that make up the system. 
Hence, as in other complex systems, emergence in indigenous evaluation results from two-way feedbacks in which outputs are recycled to become inputs in ways that either reverse the change of some variable(s) in the system (negative feedback) or enhance it (positive feedback). This summons the threshold model of social influence (Granovetter, 1983) according to which personal ties in dense networks such as found in indigenous societies are remarkably effective at inducing gradual behavioural changes since they are safer and free of high transaction costs.

Indigenous evaluations, as all evaluations, display emergence when their findings are utilised and impact on evaluands that are disproportionately more consequential than the evaluation intervention itself. This means that evaluation does matter even if not all evaluations are used. But they are far more likely to be used if they are user directed. It follows that indigenous evaluators tend to resort to intensive collective dialogue and that some of them have adopted the developmental-evaluation model that puts users in the driver seat and puts complexity ideas to work (Patton, 2011).

Specifically, the ontology of indigenous evaluation brings to the table a recognition that humans have duties to land, animals, and other living things. It is a frame of mind that resists the silencing of rivers, the destruction of watersheds, the razing of mountains for mining, the pollution of air, water, and so forth. It promotes social cohesion and it does not view self-interest as sacrosanct.

Indigenous evaluation has favoured autonomy from forces that lie beyond indigenous control (self-organisation) and it has given precedence to co-operation over competition and hierarchy. This is because the societies in which indigenous evaluation is embedded display the self-management features of other complex systems that are omnipresent in the social and natural world. In such systems, feedbacks take place through networks. 
Where positive feedback dominates, past events weigh heavily on outcomes and the path is prologue (path dependence). This is how indigenous evaluation contributes to gradual, sustainable adaptation of indigenous societies to changes in the natural environment. Thus, as in other complex systems, emergent orders arise spontaneously without external intervention and actions may be guided by the traces left by prior actions without central planning, control, or even mutual awareness (stigmergy).

This said, indigenous societies in the 21st century are not closed systems. While community networks interact with one another, they also contend with national governance networks in ways that inevitably create co-evolutionary behaviour and set limits on indigenous autonomy. Outcomes depend on order parameters present within the evaluand and control parameters that have the capacity to induce changes in the order parameters.

Indigenous evaluation in pursuit of social justice seeks to influence the control and order parameters of social interventions in the interest of indigenous communities. They are frequently subjected to systematic discrimination and assimilationist pressures. Often denied their rights to self-determination, they may also lack adequate representation in country-wide political processes so that they cannot influence crucial policy decisions that directly affect them. They face continuous challenges to their autonomy and, in some contexts, their very existence.

A frequent feature of complex systems is criticality which materialises when incremental events trigger massive systemic change due to subtle interdependencies among the system constituents. Dynamic complex systems may gravitate towards and settle into one or more possible steady states (attractors) - islands of stability in a chaotic world. Systems are considered robust when small changes in variables do not lead to highly disruptive changes because self-organisation 
helps the complex system to adapt. ${ }^{1}$ Thus, complex systems operate in a region between order and randomness - where complexity is maximal.

A system reaches a critical state if the configuration of its components and the nature of their interrelationships make the system vulnerable. Phase transitions from one system state to another can be positive, but they can also be catastrophic, as colonial history confirms. This risky state of affairs means that indigenous evaluation, unless it is limited to the assessment of relatively small interventions that are inherently protected from the overall enabling environment, is duty bound to adopt an ambiguous if not adversary or even antagonistic dialectical relationship "against" the state in which indigenous nations are embedded (Ferreira, 2018).

In particular, the intersection between state law and customary law is a highly contested terrain. It takes very different forms from country to country and it is shaped by interactions with the capitalistic modes of production that indigenous societies must inevitably contend with as well as with the residual effects of colonisation patterns associated with individual country histories and traditions. Thus, indigenous evaluation models cannot escape the need to confront nonindigenous evaluation approaches and the imperative of speaking truth to the powers that circumscribe indigenous authority.

This adds advocacy, adversary, and even subversive dimensions to indigenous evaluation practice. From this vantage point, indigenous evaluation is mandated to resist the powerful ideologies that distort mainstream evaluation practice: the very same ideologies have deprived indigenous peoples from access to natural resources, basic services, the formal economy, and equitable participation in decision making. No wonder then that indigenous evaluators are weary of

1 Unlike merely complicated physical systems, robust complex systems can adjust to changes in the external or internal environment (e.g., removal of some parts of the system). 
evaluation that disregards indigenous ways of knowing and why they insist on keeping control of their evaluation methods and processes (Kawakami et al., 2007).

\section{Confronting the dominant ideologies}

According to Michel Foucault (1977), there is no truth without power and power "produces" truth. ${ }^{2}$ Evaluation is nested within knowledge regimes and power seeks to capture it through co-optation strategies. Ultimately, power seeks normalisation and conformity in ways that make forced compulsion and violence redundant: disproportionate power makes the exercise of power unnecessary (Hoy, 2004). This highlights the critical importance of individual agency and principled resistance to socially irresponsible power through indigenous evaluation and other progressive evaluation approaches.

Hunter-gatherer societies, whether in Africa, Asia, South America, etc., had many things in common. They lived in small groups and moved to follow the available game and access edible vegetation. They maintained peaceful relations with other indigenous groups and only engaged in warfare when confronted by warlike groups. All material goods were shared. The culture was egalitarian and fiercely opposed to hierarchy; that is, collective action prevented anyone from dominating (Lee, 1988).

This egalitarian, high trust, social configuration did not survive the advent of agriculture and its corollary-property rights-that paved the way for the emergence of ternary societies where power and property became concentrated in the clergy and the nobility while work was carried out by peasants, artisans, and merchants (the Third Estate). Nor did the French Revolution - that ushered in the modern centralised state-or the Industrial Revolution — that triggered the

2 Fake news, alternative facts, and the propaganda narratives propagated by the unregulated social media are extreme manifestations of this phenomenon (Picciotto, 2017). 
ascent of capitalism — challenge property rights or abolish slaveryan institution that still survives in various forms despite its formal abolition in the nineteenth century (Piketty, 2020). ${ }^{3}$

Settler colonisation has always focused on the exploitation of natural resources (precious metals, forests, agricultural lands, animals, etc.) on which indigenous communities depend for their survival. But it has taken diverse forms. In North America, settlers sought to remove, dominate, and replace indigenous populations of sovereign Indian regimes. They did so with brutal efficiency through bad-faith negotiation, dispossession, famine, disease, and violent extermination so that by the 20 th century only 237,000 Indians remained whereas they numbered over 12 million scattered among 300 native nations in 1492 when the Queen of Spain sent Christopher Columbus on his first voyage ${ }^{4}$ (Ostler, 2019). Similarly, violent genocidal dominance ideologies drove European settlement in Central and South America.

In other countries subjected to European settlement, the emphasis of state policy was on assimilation and incorporation of indigenous peoples in the social hierarchy as landless labourers. Penitentiaries, schools, workhouses, and missionaries were mobilised to instil a "work ethic" among indigenous populations, a Victorian endeavour that paralleled similar efforts in the metropolis regarding the unwilling workers who had struggled against the new patterns of life imposed by the victorious capitalist order throughout the Industrial Revolution. But indigenous peoples have stoutly resisted the master-servant colonial model through various strategies of accommodation (e.g., casual or itinerant workers, guides, shepherds, stockmen, etc.) that often succeeded in

3 According to the International Labour Organization (ILO) two centuries after the abolition of the transatlantic slave trade, at least 12.3 million people are subjected to modern forms of forced labour-in rich countries, as well as poor ones.

4 The current Ameridian population in the US is about 6.8 million due to high fertility rates and sharp reductions in mortality rates. 
securing them a somewhat higher social status than common labourers in the metropolis (Reynolds, 1983).

Indigenous peoples often account for a disproportionate share of the prison population, their access to social services is often limited, and they are not always consulted about projects affecting their lands or about administrative or legislative measures that may affect their livelihoods. The United Nations has recognised that they face discrimination. A Declaration of the Rights of Indigenous Peoples was adopted by the General Assembly in September 2007. It emphasises self-determination, protection of cultural traditions and customs, control over educational systems, participation in decision making for matters that affect their lives and destinies, etc. Unfortunately, the Declaration is nonbinding, and its enforcement is lax.

Depending on the country context, indigenous communities face different constraints on their right to control their own development based on their distinctive histories, values, needs, and priorities. The historic Treaty of Waitangi in 1840 created a unique binational, bilingual state where Māori enjoy parliamentary representation and within which a special tribunal set up in 1975 allows Māori to seek redress for historical abuses.

In this unique context, indigenous evaluation has a key role to play in the decolonisation of evaluation. According to Kate McKegg (2019) "the field of evaluation is not immune to having a role in maintaining the dominant system of white privilege and power in Western nations" (p. 360). Privilege influences how evaluations are framed, which in turn tends to exclude the weak and underprivileged and, as a result, damages the social validity of the evaluation. Freeing evaluation from the prerogatives of power, rank, and status is hard since privilege is often invisible to those that hold it (Kirkhart, 2016).

Nor is confronting capitalist ideologies easy, since economic elites, business interests, and social researchers are often beholden to neoliberal 
doctrines of society that conceive of citizens primarily as self-interested economic actors or consumers of public services whose autonomous exertions yield socially beneficial outcomes through the providential intervention of Adam Smith's hidden hand (Mathison, 2016).

\section{Implications for evaluation}

Energised by New Public Management ideas that paradoxically originated in New Zealand, the evidence-based wave that characterises evaluation diffusion today (Vedung, 2010) has turned evaluation into a commodity subject to market forces. Currently, evaluations are mostly commissioned by power holders and evaluators are mostly tasked to produce incontrovertible evidence of verifiable "results".

Evaluators are fee dependent and constrained by terms of reference that privilege achievement of predetermined objectives set by power holders. They do not enjoy autonomy in their work since they cannot bite the hands that feed them unless they are rich or addicted to risk. They are induced to subscribe to the epistemological premise that value-free distancing from the object of study is essential to avoid bias. They are expected to hold on to antiquated views about the superiority of quantitative methods.

The commissioners who hold the purse strings stick to the ontological belief that there is only one reality, albeit one that can only be grasped within a probability range. They embrace utopian ideas about the benefits of market-based solutions to all social problems. They give privileged attention to verifying what works. They resist stakeholders' perspectives and have successfully restored the dominance of randomised control trials in evaluation methods. Yet, there is overwhelming evidence that such methods are ethically fraught, rooted in naive perceptions of policy making, constrained by severe statistical limitations, and inappropriate for complex interventions (Picciotto, 2012). 
While a paradigm shift towards complexity is well underway in the international scientific enterprise, most policy makers remain committed to a linear, postpositivist conception of evaluation. Revealingly, there is no word for "linear" in some indigenous languages since "nobody would consider travelling, thinking, or talking in a straight line in the first place. The winding path is just how a path is, and therefore it needs no name" (Yunkaporta, 2019, p. 20). Nor do indigenous cultures wedded to infinite and regenerative connections among open systems view society as a closed system that demands infinite growth (and therefore ultimate annihilation) through ruthless exploitation of natural resources.

Thus, indigenous evaluators readily embrace complexity thinking as a strategy for pushing back the frontiers of knowledge (Mikulecky, 2001). They give pride of place to the relational context of the evaluation process. They reject the illusion of scientific omniscience-just as quantum physicists do. By contrast, the currently dominant evidence-based evaluation model is wedded to simplistic "results chain" thinking and it is narrowly constructed in a context of parochial privilege that tags and displays indigenous wisdom as exotic and primitive, a self-damaging, culturally insensitive stance that undermines the social validity of evaluation findings and recommendations.

Finally, indigenous evaluation is transdisciplinary. Mixed methods that give pride of place to genuine participation and dialogue are privileged by indigenous evaluators. This puts interactions within the community at the centre of the evaluation stage in ways that amplify the voices of all community members and use evaluation to strengthen social cohesion and challenge the hegemonic ideas that have, for far too long, generated social injustice and environmental destruction. 


\section{Conclusion}

The complexity turn is more than a fad. It is part of a fundamental paradigm shift in all the sciences and it has only begun to transform evaluation practice. Indigenous evaluation has much to contribute to this shift through a fundamental reorientation of evaluation policy directions. It promotes sustainability by respecting nature and all living beings. It is committed, spirited, and open to fresh ideas. It is multidisciplinary and adaptable. It embraces diversity, sharing, and tolerance. It rejects the self-important narcissism of power holders ... and it ignores the pronouncements of evaluators addicted to single narratives and rigid methodological dogmas. It works effectively in a wide range of local contexts. It also has a global reach. Isn't it time for the rest of the evaluation community to take notice?

\section{References}

Apgar, J. M., Argumedo, A., \& Allen, W. (2009). Building transdisciplinarity for managing complexity: Lessons from indigenous practice. International Journal of Interdisciplinary Social Sciences, 4(5), 255-270. https://doi. org/10.18848/1833-1882/CGP/v04i05/52925

Ferreira, A. C. (2018). Societies 'against' and 'in' the state—from Exiwa to the Retakings: Territory, autonomy, and hierarchy in the history of the indigenous peoples of Chaco-Pantanal. Vibrant: Virtual Brazilian Anthropology, 15(2). https://doi.org/10.1590/1809-43412018v15n2a408

Foucault, M. (1977). Discipline and punish: The birth of the prison. Random House.

Granovetter, M. (1983). The strength of weak ties: A network theory revisited. Sociological Theory, 1, 201-233. https://doi.org/10.2307/202051

Hoy, D. C. (2004). Critical resistance: From poststructuralism to post-critique. The MIT Press. https://doi.org/10.7551/mitpress/2217.001.0001

Kawakami, A. J., Aton, K., Cram, F., Lai, M. K., \& Porima, L. (2007). Improving the practice of evaluation through indigenous values and 
methods: Decolonizing evaluation practice—returning the gaze from Hawaii and Aotearoa. Hülili: Multidisciplinary Research on Hawaiian Wellbeing, 4(1), 319-348.

Kirkhart, K. E. (2016). Equity, privilege, and validity: Traveling companions or strange bedfellows. In S. I. Donaldson \& R. Picciotto (Eds.), Evaluation for an equitable society (pp. 109-131). Information Age Publishing.

Latour, B. (1991). We have never been modern. Harvard University Press.

Lee, R. B. (1988). Reflections on primitive communism. In T. Ingold, D. Riches, \& J. Woodburn (Eds.), Hunters and gatherers (vol. 1, pp. 252-268). Oxford University Press.

Mathison, S. (2016). Confronting capitalism: Evaluation that fosters social equity. In S. I. Donaldson \& R. Picciotto (Eds.), Evaluation for an equitable society (pp. 83-107). Information Age Publishing.

McKegg, K. (2019). White privilege and the decolonization work needed in evaluation to support indigenous sovereignty and self-determination. Canadian Journal of Program Evaluation, 34(2), 357-367. https://doi. org/10.3138/cjpe.67978

Mikulecky, D. C., (2001). The emergence of complexity: Science coming of age or science growing old? Computers and Chemistry, 25(4), 341-348. https://doi.org/10.1016/S0097-8485(01)00070-5

Ostler, J. (2019). Surviving genocide: Native nations and the United States from the American revolution to bleeding Kansas. Yale University Press. https:// doi.org/10.2307/j.ctvgc629z

Patton, M. Q. (2011). Developmental evaluation: Applying complexity concepts to enhance innovation and use. Guilford Press.

Pearl, J., \& Mackenzie, D. (2018). The book of why: The new science of cause and effect. Basic Books.

Picciotto, R. (2012). Experimentalism and development evaluation: Will the bubble burst? Evaluation, 18(2), 213-229. https://doi. org/10.1177/1356389012440915 
Picciotto, R. (2017). Evaluation: Discursive practice or communicative action? Evaluation, 23(3), 312-322. https://doi. org/10.1177/1356389017714384

Piketty, T. (2020). Capital and ideology. Harvard University Press.

Reynolds, Henry. (1983). Aborigines and European social hierarchy. Aboriginal History, 7, 124-133.

Vedung, E. (2010). Four waves of evaluation diffusion. Evaluation, 16(3), 263-277. https://doi.org/10.1177/1356389010372452

Yunkaporta, T. (2019). Sand talk: How indigenous thinking can save the world. Text Publishing.

\section{The author}

Robert Picciotto, a graduate of the Ecole Nationale Supérieure de l'Aéronautique and of the Princeton School of Public and International Affairs, retired from the World Bank after holding the positions of Vice-President, Corporate Planning and Budgeting and of DirectorGeneral of the Independent Evaluation Group. He is now adjunct professor, University of Auckland.

Email: R.Picciotto@jeunot.net 